\title{
Measurement of Social Networks for Innovation within Community Disaster Resilience
}

\author{
Joanna Wilkin $^{1, *}$, Eloise Biggs ${ }^{2}\left(\mathbb{C}\right.$ ) and Andrew $\mathrm{J}_{\text {Tatem }}{ }^{1}$ \\ 1 WorldPop, Geography and Environmental Science, University of Southampton, Southampton SO17 1BJ, UK; \\ A.J.Tatem@soton.ac.uk \\ 2 School of Agriculture and Environment, University of Western Australia, Crawley 6009, Australia; \\ eloise.biggs@uwa.edu.au \\ * Correspondence: jw3e15@soton.ac.uk
}

Received: 25 February 2019; Accepted: 29 March 2019; Published: 2 April 2019

\begin{abstract}
Disaster risk reduction (DRR) research has long recognised that social networks are a vital source of support during and after a shock. However, the quantification of this social support, primarily through its recognition as social capital, has proven problematic as there is no singular method for its measurement, invalidating the credibility of studies that try to correlate its effects with community disaster resilience. Within the wider resilience field, research that specifically utilises social networks as the focus of analysis is evolving. This paper provides a critical synthesis of how this developing discourse is filtering into community disaster resilience, reviewing empirical case studies from the Global South within DRR that use social network analysis and connectivity measurement. Our analysis of these studies indicates that a robust methodology utilising social network analysis is emerging, which offers opportunity for research cross-comparability. Our review also finds that without this bottom-up mapping, the implementation of top-down preparedness policy and procedures are likely to fail, resulting in the advocation of social network analysis as a critical methodology in future resilience research and policy planning.
\end{abstract}

Keywords: community disaster resilience; social networks; connectivity; disaster risk reduction; social network analysis; social network mapping; data; innovation

\section{Introduction}

Community resilience is broadly understood as the capacity for a community to be able to recover from a shock (such as a disaster), as well as its capability to undergo transformative changes using self-organisation and collective action to deal with impact [1], and adapt as needed in order to move on from the shock. Building and strengthening resilience within vulnerable communities is a key priority for those working with disaster risk reduction, including the International Federation of the Red Cross (IFRC) [2], the World Health Organisation (WHO) [3], and the United Nations Office for Disaster Risk Reduction (UNISDR) [4]. Traditionally, these resilience building efforts have focused on the physical and financial aspects of a community, such as improving infrastructure or diversifying livelihood strategies [5]. However, a renewed focus on disaster response and recovery by the Sendai Framework for Disaster Risk Reduction (2015-2030) [6] and recent disasters worldwide where social support has been at the forefront of recovery strategies, has put the attention on alternative aspects of community resilience.

Disaster risk reduction (DRR) research fully acknowledges that communities regularly work together to survive and recover from catastrophic impacts [5]. Recent disaster events have highlighted the important role of social support, in which civilians, i.e., persons who are not trained responders or workers from relief agencies, through the provision of aid and supplies, are involved in the immediate 
response as well as help with longer term recovery (e.g., the 'Cajun Navy' during the 2017 floods in Houston, Texas). This community-based help and support is underpinned by the following tenets of social capital: Cooperation and collective action is facilitated by the participation of individuals and communities within different types of social networks, as well as by the trust and belief within and between these networks that this help would be reciprocated if and when needed, creating a sense of goodwill towards one another [7]. This support can come from relationships within the affected communities or through linkages to other communities. However, the quantification of this social support for community DRR, primarily through its recognition as social capital, remains problematic. Despite the first discussions of the concept arising more than thirty years ago (beginning with Bourdieu's 1986 'the forms of capital' [8]), social capital has not found solid singular ground in its definition or its measurement [9]. Inconsistencies also lie within community resilience studies, where resilience itself is, similarly, yet to be operationalised under one common method or measure [10].

A growing discourse of research that specifically investigates people's social networks as a core component of community resilience has filtered into DRR research, with the driving interest for DRR researchers working in the Global South being that "the social networks of the poor are one of the primary resources they have for managing risk and vulnerability" [11] (p. 242). Unlike previous approaches to measuring social capital, either as a standalone concept or within community resilience, these studies have followed a similar approach to measurement. Such research has attempted to capture the level of help and support within a community by assessing the structure of their social networks, considering different characteristics (e.g., the number and types of relationships) and their overall connectivity. The premise is that the presence, strength, and effectiveness of social networks will directly influence the ability of communities to cope with disaster events [12] and this can be quantified through a structural network-based approach.

To encourage engagement with this relatively new discourse, we provide a much-needed synthesis of empirical research to evidence the relationship between social networks and community resilience within DRR and advocate for its use within community disaster resilience measurement. The paper builds this evidence through the critical appraisal of eleven case studies from the Global South, assessing their methodologies and their findings, to demonstrate the utility and importance of emerging social network approaches. Our review identifies that a singular methodology is developing around social networks and connectivity within community disaster resilience. Furthermore, the paper's consolidation of the main findings of the case studies indicate that the use of social network-based methodologies is invaluable for practitioners to understand how community resilience is built from the bottom-up. The paper provides substantive evidence that without an understanding of local social structures within a community in the Global South, any top-down implementation of preparedness policy and procedures, such as introducing a community disaster committee, are likely to fail. As a result, this paper proposes that the use of social network mapping and analysis should be promoted and utilised more widely within resilience research and potential policy-influenced programming. To encourage the uptake of these social network approaches as a common resilience measure, this paper provides suggestions on how future studies should develop in order to better understand the role of social networks in disaster response, which can further enhance this bottom-up understanding of community resilience.

\section{Current Limitations of Operationalising Social Capital Within Community Disaster Resilience}

The resilience of communities is a prominent topic within the agendas of development, humanitarian, and DRR policy makers today [1]. Resilience continues to appear in various programmes for action, from the aforementioned Sendai Framework for DRR as well as the Sustainable Development Goals, where it is explicitly acknowledged in Targets 1.5 (By 2030 build the resilience of the poor and those in vulnerable situations, and reduce their exposure and vulnerability to climate-related extreme events and other economic, social and environmental shocks and disasters. Source: UN, 2015.) and 13.1 (Strengthen resilience and adaptive capacity to climate-related hazards and natural 
disasters in all countries. Source: UN, 2015.), as well as implicitly underpinning the achievements of several other targets [13]. These programmes renew the intention to focus on building resilience within and into communities. However, despite efforts to incorporate resilience into policy making and program planning, the evidence guiding these developments is limited in its representation of community resilience, particularly as a process a community undertakes and not just a property that a community has [14]. Primarily, these shortcomings are rooted in a lack of cohesion in the definition and measurement of resilience within and across these different fields. Even the word resilience has a long and fraught modern history, resulting in an amount of literature "so copious that it is becoming increasingly difficult to summarise" [15].

In this paper we broadly define resilience to be the ability of a system to (i) respond to, or have the capacity to absorb, a disturbance and still retain its basic structure, functions, and processes, (ii) self-organize, and (iii) build capacity for learning and adaptation [16-18]. For DRR, we further this definition to focus on an individual or population being able to absorb and recover from a shock by anticipating and dealing with the impact of a natural hazard, using self-organisation to help as well as having the capacity to adapt to change. Our definition follows core DRR resilience concepts proposed by Manyena et al (2011), stating that following a disaster, individuals, communities, and systems have the intrinsic ability to 'bounce forward' [19] the ability of a community to rebuild (preferably better) as part of their capacity to adapt and learn. Scale and geography is also embedded into our considerations and definition of a community. As disasters are local events, they will impact each local geographical community differently as well as require and trigger different responses by these communities [20]. Consequently, for community disaster resilience to ensue, the ability for a community to recover from and resume normal activities in the aftermath of a shock is primarily determined by their resilience [21-23].

The last decade has seen researchers and practitioners attempt to capture and measure community disaster resilience as an absolute characteristic and as a relative asset through both quantitative and qualitative approaches. At the forefront has been the development of composite indicators to assess the proposed capacities of a resilient community, such as economic development, community competence, functioning infrastructure, and organisational capability [23-27]. These indicators use existing empirical variables (such as gross domestic product, percentage of the population over 65, housing types, and insurance coverage) to construct a single indicator of resilience; however, there is no 'one' method to determine individual variables or derive a composite measure. A review by Beccari (2016) analysed over 100 composite indicators that were related to resilience and identified 2298 unique variables covered by 106 different methodologies [28]. Further reviews [10,29,30] have developed frameworks on how to build community resilience composite indicators based on consolidating current approaches, but one singular approach is yet to be adopted, preventing measurements from being compared across countries, across time periods, and with other research. There are also continuing limitations with these indicators to take into account cross-scale relationships, as well as dynamics over time and across space [29].

Within these different indicators, social support is identified as a key capacity of a resilient community. Recent papers have advocated that social support in the form of social capital is a fundamental capacity that could be used to enhance a community's resilience $[5,20]$. Focusing on social capital for operationalising community resilience, however, creates its own problems, which are primarily caused by the ambiguity in and variance of social capital as a concept, its definition, and its operationalisation [9].

Social capital was originally conceptualised by Bourdieu (1986) as one of many forms of capital (e.g., financial, cultural etc.) that an individual possesses and utilises to make advancements in their life [8]. Social capital is the aggregate of the actual or potential resources that are linked to an individual through their possession of a durable social network i.e., good relationships with family, friends and acquaintances [8]. Each member within this social network has the backing of the collectively-owned capital and are entitled to utilize these resources as and when required. For community disaster 
resilience, social capital drives the social support and collective action of individuals and communities helping one another. The support is provided under the notion of what Lin (1999) identifies as an investment in social relations with expected returns [31], where one community is motivated to help another in the understanding that help will be returned, whether in smaller, equal, or greater measures, should it be required in the future.

Social capital is therefore created through the presence of social networks, as well as the trust and norms inherent within them, that create a sense of goodwill and facilitate cooperation. The amount of social capital present depends on the size of the network present (i.e., the number of relationships) and whether these relationships can be mobilized, in conjunction with other types of capital possessed by each member of the network. This network can be at the individual or the group scale, including communities and societies which have the tendency to form and benefit from these reciprocal networks [32]. Social capital is thus normally conceptualised by the following two core components or dimensions: The structural aspect, which incorporates the connections, groups, and networks of social relations, and the cognitive aspect, the mobilization and reciprocity underpinned by the norms, values, and trust [7].

Whilst there is a general agreement on how social capital works, quantifying it is made difficult by the problem of separating its source, form, and consequences for measurement $[7,33]$. For example, whilst social capital is created through the presence of trust, is trust a source, a form, or a consequence? As arguments could be made for each, evaluating these aspects simultaneously has caused ongoing operationalisation issues as researchers try to define what creates social capital, what sustains it, and what it provides.

Consequently, most empirical studies have measured social capital through indirect indicators, such as crime rates, teenage pregnancies, or participation rates, that are believed to be associated with the presence (or lack) of social capital as a whole [34]. These indicators however do not measure social capital as a source or as a form and as a result, it is argued that these indicators cannot truly represent the intrinsic social capital the population possesses [33]. There are more holistic approaches to measuring social capital, such as the World Bank Social Capital Assessment Tool (SOCAT) (1999) [35]. These surveys attempt to capture individual-based perceptions on social capital, asking questions on group membership, social norms, and support, as well as the more cognitive side, including trust and reciprocity and aggregate responses at the community level [9]. However, these surveys again do not attempt to separate the outcomes of social capital from its source or form. Overall, research remains divided on whether such measurement is possible. A recent review by Alvarez and Romani (2017) concluded that no further progress towards a standardised measure has been made since initial research at the start of the millennium [9]. Without a singular way to operationalise social capital, it continues to be a theoretical concept [36], with its conceptual vagueness partly invalidating the credibility of empirical and theoretical studies that evaluate its possible effects [34].

For the DRR community, this doubt in credibility is magnified by the prominent use of these indirect indicators within the aforementioned composite indicators of community resilience. Buoyed by the ease of their extraction from publicly available sources of data, such as national censuses and surveys [5], it is common to see indirect indicators of social capital, such as participation in volunteer organisations or number of religious organisations within the population, used within community resilience composite indicators (e.g., [23,26]). With both the chosen social capital indicator or indicators and the composite community resilience indicator having weak epistemological foundations, it is questionable that the resulting data actually relates to the phenomena in question-the ability for a community to respond, absorb, and/or recover from a shock and bounce back better. Furthermore, for those in resource-poor settings, such as the Global South, national population and census data are often outdated, inaccurate, or missing key groups or areas [37], which reduces the likelihood of these datasets being available to use within these indicators. As a result, there are significant epistemological and logistical challenges to operationalising social capital within community disaster 
resilience under one clear, consistent, and overarching method for its use within and across national policy and global programming.

\section{Social Networks and the Evolution of a Cohesive and Robust Methodology}

To overcome these limitations, it is proposed here that a growing body of literature is focusing solely on the role of social networks, rather than social capital, as a potential measurable approach to assessing and targeting community disaster resilience. The premise is that the presence, strength and effectiveness of social networks will directly influence the ability of communities to cope with disaster events [12], which can be quantified through using a structural or network-based approach. This approach is primarily achieved by interviewing individuals or households within the community to collect information about their relationships using interviews or questionnaires. These relationships can be between individuals or households within the community as well as with external connections. Building networks generally follow one of three methods, collecting data on the following: All possible members of the community; a random sample of those within the community; or use a 'snowball' approach by collecting data only on those mentioned by a random 'starter' group within the community [38]. Once the data are collected, the networks can then be constructed and analysed to assess the overall connectivity of the community.

Social network analysis (SNA) emerged from the confluence of research within three different traditions over a forty year period, including sociometric analysts, who provided many technical breakthroughs on the methods of graph theory, researchers from the 1930s, who were focused on the patterns of interpersonal relations and their role within the formation of cliques, and finally social anthropologists, who built on both of these to study the role of community structure and relations within village societies [39]. Contemporary SNA utilises matrices and sociograms (see Figure 1), where networks are represented by lines (relationships) and points (the actors within the network e.g., individuals, households), which are then mathematically analysed using aspects of graph theory. These mathematical quantifications are then connected with a specific sociological or anthropological concept or theory to evaluate the role of the network being considered. This connection was solidified in the seminal work of Mark Granovetter's (1973) sociological article on 'the strength of weak ties', where basic social network analysis (SNA) methods were used to explore not only the importance of close friendships, but also the role of weaker connections to improving personal outcomes [40]. The work was of central importance for popularising and legitimating SNA as a methodology, contributing to its systematic and analytical development, and showed the power of even the most basic of SNA methods for exploring social structure [39].

CREATING SOCIAL NETWORK MAPS (SOCIOGRAMS)

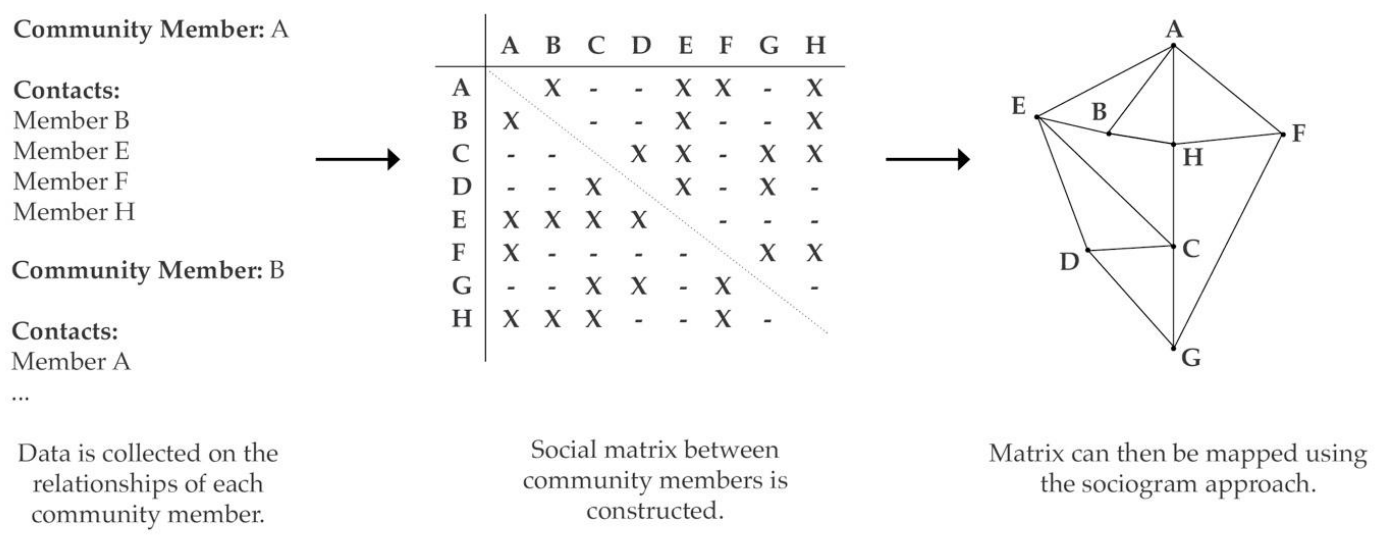

Figure 1. Creating social network maps from data collected on hypothetical community member relationships. 
SNA has featured within social capital theory. Lin et al (1981) pursued the connection between SNA and social structure with social capital, suggesting that the access to and use of social resources by an individual would be, in part, determined by their position within the network's hierarchical structure and by their ability to use their weaker ties [41]. Burt continued to develop much of this work, theorising that certain network positions have significant effects on an individual's ability to realize benefits [42]. The size or degree, the density, the heterogeneity, and a number of other hierarchical characteristics of an individual's network were, as a result, all considered important measures when evaluating an individual's social capital from a structural viewpoint [33]. These measures are detailed further in Table 1, where their role in enhancing or reducing the amount of structural social capital is linked.

Table 1. Network-based measures and their relation to structural social capital.

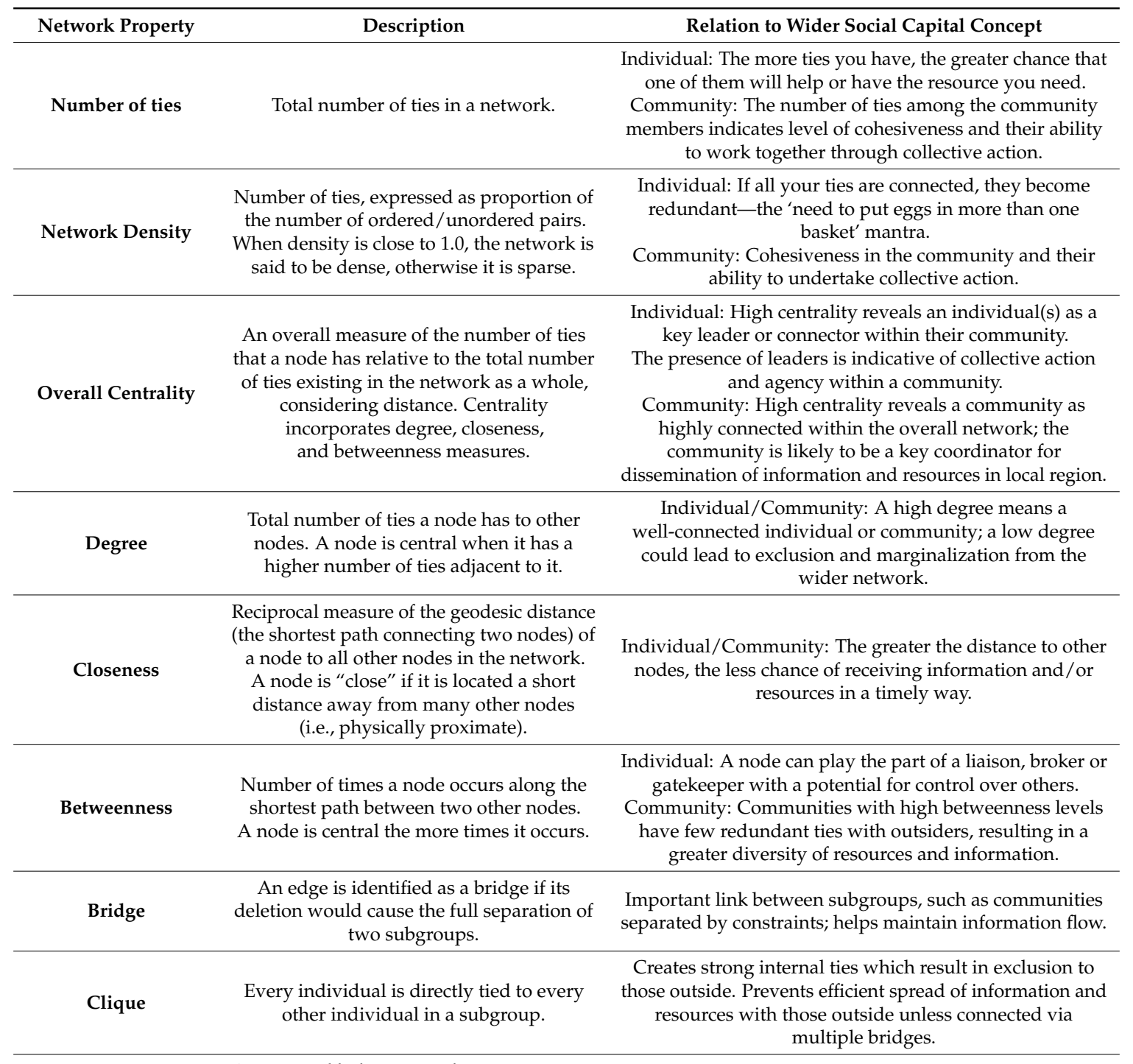

A structural hole occurs whenever a person

(i) has a relationship with someone who is

Structural hole connected to a separate subgroup of people

and (ii) has no other direct or indirect connection with the people in

More structural holes in a network is likely to result in exposure to more diverse information and opportunities than a network having relatively few structural holes. that subgroup. 
The use of these network-based measures (NBM) however was not sufficient to measure social capital as a concept. NBM are merely a mathematical evaluation of a network structure; they do not provide information on the quality of the relationships or the more cognitive aspects of social capital, such as the trusts and norms within a community and, as a result, introduce ambiguity regarding what is actually being measured when it comes to social capital [33]. NBM therefore do not solve the ongoing dilemma of whether the social networks are a source, form, or consequence of social capital. As a result, NBM can only reveal how relatively well an individual or group is connected and placed within a network and then estimate or assume the implications of this for social capital outcomes, such as agency and collective action. For example, do certain types of network structure have the tendency to facilitate collective action through their very structure? Ultimately, NBM must be linked with other measures of norms, trust, and reciprocity to provide 'local and contextual measurement' [35], in order to assess social capital. As a result, these limitations of this structural approach prevented NBM from becoming an overriding methodology to evaluate social capital.

Despite these shortcomings in measuring social capital as a concept, the influence of social networks, network structure, and connectivity on the ability of a community to deal with stresses and shocks has not been discounted. A review of 80 papers on community resilience by Patel et al (2017), for example, found that community networks/relationships was one of nine core elements of a resilient community most commonly cited within research. It is apparent, therefore, that literature on social networks has developed outside of the main body of literature on social capital. In fact, a recent review, by Rockenbauch and Sakdapolrak (2017), of 60 empirical case studies that focus on the role of social networks within the general resilience of rural communities in the Global South, found that less than half ( $40 \%)$ of these conceptualised the role of social networks as social capital [44]. Instead, social networks were seen either as a form of coordination, connecting people, or as pipe, connecting flows of resources, information, and knowledge. This focus on social networks and connectivity as a means for communities to deal with external stresses, shocks, and risks is also reflected in a high prevalence of structurally-explicit analyses within the review. A total of 26 out of the 60 papers used some form of NBM methodology to evaluate the community's resilience. Furthermore, three-quarters of these papers $(20 / 26)$ also used the same NBMs within their methodologies. The number or degree of ties, the density of the network, and the overall centrality were all used to evaluate the connectivity of the social networks. The review also showed that there was consistency in the units of analysis used, including which type of actors were studied (individuals, households) and at what scale (community, regional). The findings indicated an increased focus on the role of network connections and structure, rather than social capital. The studies also revealed methodological consolidation around specific NBMs, which together formed a consistent and overarching approach to assessing social networks as a key determinant of a community's resilience.

The implications of Rockenbauch and Sakdapolrak's (2017) research for DRR are important. The review shows that, in the wider resilience literature, a common, robust, and replicable methodology is developing that looks to measure social networks, network structure, and connectivity for resilience estimation. Furthermore, with their focus on the Global South sparked by the frustration that "the role of social networks for resilience of rural communities remained an under researched and under conceptualised issue, with research scattered between different strands and rarely integrated from a resilience perspective" [44] (p. 1), their review provides a significant step towards consolidating this current disparate research under a singular canon of work. This prioritisation of social networks, rather than social capital, encourages researchers to move away from capturing an immeasurable concept and its associated debates (particularly concerning whether networks are a source, form, or consequence of social capital) to highlighting instead the importance of social connectivity and how different types of social networks and structures can contribute towards or even determine a community's resilience within the Global South. 


\section{Mapping Social Networks for Community Disaster Resilience}

This move towards social networks, rather than social capital, as a core component and focus of analysis has started to filter into research on community disaster resilience. As Misra et al. (2017) suggested in their own case study, whilst the application of NBM and the use of SNA as a methodology is relatively new for community disaster resilience, it can be anticipated through a reflection on the emerging literature [12]. Here we provide a review of several case studies that have used NBM and SNA to assess community disaster resilience to evidence this growing field of research. To enable comparison with and to build on the findings of the Rockenbauch and Sakdapolrak (2017) review, our analysis used the same methodology to assess how each selected case study conceptualised and operationalized social networks specifically within disaster resilience (Table 2), a 'strand' not covered by their review.

Table 2. Categories used to assess recent research which has analysed social networks; based on Rockenbauch and Sakdapolrak's methodology [44].

\begin{tabular}{ccc}
\hline & Category Applied & Questions Addressed \\
\hline Conceptualisation & Conceptual Framing & Is resilience addressed implicitly or explicitly? \\
& Network variable & How are social networks and resilience framed? \\
& Network narrative & Are social networks treated as dependent or independent variables? \\
Operationalisation & What is the underlying conception of social networks? \\
& Network approach & What operational approach does the study follow? \\
& Network definition & What are the social relations of interest? \\
& Network analysis & Who are the actors and what are the relevant scales of interaction? \\
& & On what network level does the analysis focus? \\
& & What network characteristics are addressed? \\
Key findings & What key findings can be summarized regarding the question of \\
& & com social networks relate to aspects relevant to the resilience of rural \\
& & communities? \\
\hline
\end{tabular}

Our initial literature base was found through searching the Web of Science database [45], using a combination of the terms "social network" or "social capital" and then "community resilience" and "disaster risk reduction". The literature retrieved was filtered to only retain papers that focused on topics such as disaster preparedness, disaster response, disaster impact, and adaptive capacity. This was to ensure our review provided complimentary findings to the three resilience 'strands' covered by Rockenbauch and Sakdapolrak's review (natural resource governance, agricultural innovation, and general social support) and focused on the specifics of community disaster resilience. From the resulting DRR literature, case studies were then selected as per the criteria of Rockenbauch and Sakdapolrak's review, as follows: Peer-reviewed articles published in English from January 2000 (and in this case, the time period extended to May 2018), which only include empirical articles containing the analysis of data and only select those with case studies from the Global South, based on the categories "low-income" and "middle-income" countries from the World Bank [46]. The latter parameter removed five case studies, of which the majority of research had occurred in the United States, specifically in response to Hurricane Katrina. The Nakagawa and Shaw (2004) article was retained for analysis, despite the inclusion of Japan as a case study. The premise of the paper was that a model was developed for Kobe, Japan and then applied to Gujarat, India [47]. As a result, the methodological approach was the same and the findings recorded primarily relate to the Gujarat case study. In total, 11 case studies were selected for analysis, the comprehensive results of which are found in Table S1 (Supplementary Materials).

The analysis of the literature found that community disaster resilience research involving NBM and SNA in the Global South has primarily focused on the assessment of the strength of relationships within and between communities. The studies also evaluated the role of key actors, respective social positions of community members, and, in some scenarios, the assets and resources exchanged within the network. Five of the studies sought to explicitly compare the influence of these networks and 
positions directly with their impact on resilience. In terms of framing, only four case studies saw the role of social networks as solely creating, forming, or resulting in social capital, or in the case of Minamoto (2010), structural social capital. Instead, the majority of studies focused on social networks as connections or pipes, with studies aiming to 'connect the dots' [48] and focus on 'the ties that bind' [49]. Within these studies social networks were seen as a means of accessing and exchanging resources, information, support, and knowledge. Furthermore, there were also two studies that framed social networks by connecting these functions directly with social capital, e.g., social networks mobilise social capital by providing a form of coordination and by acting as pipes they help realise the benefits of social capital [12,50].

Overall social networks were primarily treated as an independent variable, where they are seen as the basic social units to respond to disaster [51]. Two of the studies however considered how social networks themselves are actually dependent on, and often the product of, various underlying social structures and processes (such as large scale migration) [52], as well as continually affected by ongoing exposure to hazards and disasters [53]. Several of the papers also sought to make a distinction between the different types of networks present, categorising them into the three following types: Bonding, bridging, and linking networks. These different types of networks, as outlined in Table 3, were primarily distinguished by the way in which an individual, group, or community is connected to another [54]. For several of the studies the importance of these different network types was how and when they would be used in which situations and for what purposes [55], with each having a specific role within the disaster management cycle [51,53]. For example, Misra et al (2017) found that, in the early phase of a disaster, most of the response comes from social network ties within the community, but in the aftermath, the networks assumed different forms and took on different roles [12]. One paper also sought to classify the different larger-scale networks that these types of social networks usually form with one another, using their own terminology, including closed networks (dense bonding and bridging networks), extended networks (dense bridging networks), sparse networks (dispersed bridging networks), and subgroup networks (strong bonding networks with adequate bridging networks) [53].

Table 3. The different types of social networks. Adapted from $[20,56,57]$.

\begin{tabular}{|c|c|c|c|}
\hline Type of Social Network & Bonding Social Networks & Bridging Social Networks & Linking Social Networks \\
\hline Structural form & $\begin{array}{l}\text { Strong ties, usually between } \\
\text { family, close friends and } \\
\text { local community. }\end{array}$ & $\begin{array}{l}\text { Weak ties, usually between } \\
\text { members of different } \\
\text { communities and groups. }\end{array}$ & $\begin{array}{l}\text { Weak ties but across different } \\
\text { types of 'formal' agents, i.e., } \\
\text { government agencies or } \\
\text { organisations. }\end{array}$ \\
\hline $\begin{array}{l}\text { Network structure and } \\
\text { power relations }\end{array}$ & $\begin{array}{l}\text { Horizontal and } \\
\text { collaborative-relationships } \\
\text { are across the community } \\
\text { with individuals at the same } \\
\text { power level. }\end{array}$ & $\begin{array}{l}\text { Horizontal and } \\
\text { collaborative-relationships } \\
\text { are across communities with } \\
\text { individuals at the same } \\
\text { power level. }\end{array}$ & $\begin{array}{l}\text { Vertical and } \\
\text { hierarchical—relationships } \\
\text { are between the community } \\
\text { and official governmental } \\
\text { actors who have access to } \\
\text { different levels of power. }\end{array}$ \\
\hline Network composition & $\begin{array}{l}\text { Homogenous-background, } \\
\text { experience and motivation } \\
\text { to help one another are } \\
\text { similar. }\end{array}$ & $\begin{array}{l}\text { Heterogeneous-background, } \\
\text { experience and motivation to } \\
\text { help one another are } \\
\text { different. }\end{array}$ & $\begin{array}{c}\text { Heterogeneous-background, } \\
\text { experience and motivation to } \\
\text { help one another are } \\
\text { different. }\end{array}$ \\
\hline $\begin{array}{l}\text { Resources (e.g., initial } \\
\text { medical aid, shelter and } \\
\text { sustenance, or long-term } \\
\text { financial assistance and } \\
\text { mental support) }\end{array}$ & $\begin{array}{l}\text { Similar (access to initial } \\
\text { response supplies likely } \\
\text { determined by geography). }\end{array}$ & Diverse. & $\begin{array}{l}\text { Diverse and potentially } \\
\text { unlimited. }\end{array}$ \\
\hline
\end{tabular}

To classify these networks, the majority of papers sought to capture an understanding of the social networks present and used by the community in everyday and emergency situations. The majority of papers (6) used a descriptive approach, using interviews and household surveys to gather information on the role of social relations and their outcomes in previous emergency situations [51]. Different types of social ties were recorded that could then be classified into one 
of the three network types, e.g., [47,51,55], although precise ties between members of the community were not covered. A structurally-explicit approach, where these ties were recorded, was employed by just under half of the studies (5). Of these five, four were published in the last three years. The more recent use of NBM and SNA substantiates Misra et al.'s (2017) assertion that the use of the methodology in community disaster resilience is relatively new [12]. Whilst undertaking a descriptive approach, Zhao (2013) also captured individual ties of the network studied; however, this only included the size and composition of the network and did not have the required detail (who knew who) to create the social matrix and, thus, use SNA or NBMs to assess them [50]. The majority (4) of these studies focused on capturing ties within a community or within several communities, i.e., focused on bonding social networks. Only one study was able to provide cross-community analyses of bridging networks [53]. As a result, the majority of these structural-based approaches focused on looking at the importance of key actors and a member's relative positions to these central nodes within a bonding network, e.g., $[12,48,49]$.

Across the case studies, the connections within and between communities and community groups and how they form support networks to facilitate the response, recovery, and adaptation to disaster were the main social relations of interest. In addition, several papers also looked at the relationships the communities had with formal organisations (linking networks), such as non-governmental organisations and governmental departments [51,52]. The primary actors were either individuals or households within the community, although three of the papers also looked at community groups $[47,51,52]$. All of the analyses were conducted at the community scale, with the five structural approach studies capturing social ties from either individuals or household actors, within their village or community. Of these five studies, four used the same NBMs discussed above in Rockenbauch and Sakdapolrak's review, number of ties, density, and centrality, as measures to assess the social networks. The fifth paper, as outlined earlier, utilised their own method of classifying networks, although this would have been reliant on using the same NBMs to achieve this classification. In addition to the information on social ties, several of the descriptive and structural studies recorded other attributes of each actor, including gender, age, location (urban versus rural), religion, ethnicity, and socioeconomic status, to evaluate whether these attributes had any type of influence on the social networks $[14,47,48,50,51,53]$.

The majority of the studies found that, for communities in the Global South, an individual's, household's or a community's social networks are increasingly seen as the basic unit to respond to disaster [51] and that their strength and effectiveness influences the ability of the individual/household/community to respond to disaster [12]. The consensus across the studies was that social networks positively affected community recovery and resilience by mobilising and providing support, resources, and information to those at need and could even compensate for weaknesses in a wide variety of factors that led to reduced resilience and increased risk [14], e.g., failing governmental DRR policy. In fact, the studies overwhelming concluded that failing to consider the local community, their network structure, and their power relations could seriously hamper and even damage how these networks act as a resource for the community during a disaster, putting the communities in greater danger if hit by a disaster [12,51,52]. A further finding of many of the studies was that leadership within the community was particularly important to foster collective action. Without leadership or central players, there could be a lack of trust and coordination among members $[12,47,48]$, even if their social networks, from a structural perspective, would be considered to be 'good' (e.g., a high density of social relations with few structural holes or bridges).

The evaluation of these case studies by this paper provides several new findings to build on Rockenbauch and Sakdapolrak's review. Firstly, our review indicates that a common methodology is developing around SNA within DRR that corresponds with the approaches documented by the 2017 review. The structurally-explicit studies reviewed here utilised the same NBMs and assessment of social networks as those found within the 2017 review. The synergy between these different strands of research, all within the resilience canon, suggest that SNA and NBM are providing a first step 
towards a repeatable and robust methodology for community resilience estimation. By moving away from social capital, focusing on a methodology that prioritises social networks, network structure and connectivity "holds promise for theorising and analysing resilience" [58] (p. 116), not least because it can bring together and integrate different strands under the resilience perspective.

Secondly, and specifically to this review and DRR, the case studies showed that it is not only important to understand what different types of networks exist (bonding, bridging, and linking), but also how they operate at different points of the disaster management cycle, and how these can either help or hinder a response. For example, a community with a strong bonding network can result in a substantial internal response to a shock; however, if they have weak bridging or linking networks, they will be unlikely be able to access any help or resources beyond their initial community. The presence of these three network types, therefore, can be advantageous or harmful in routine and emergency situations [55]. As a result, across future DRR and community disaster resilience research, it is imperative that these three network types are assessed across the different timepoints during the response to and recovery from a disaster [51]. Furthermore, two of the case studies provide critical reflections on how independent a social network truly is and highlight that any network should be viewed and analysed in light of its ongoing social, economic, geographic, and political context $[52,53]$.

Separate from the Rockenbauch and Sakdapolrak's (2017) review, this evaluation provides a practical understanding of why social networks and social network mapping should be used within community disaster resilience research in the Global South. Mapping the community's networks, including their external relations, provides a clearer picture of the community structure and the role of local actors and local networks [49], which can then be directly linked with particular resilience features [44]. For researchers and practitioners alike, these case studies showed that social network mapping is an imperative step to understanding how community disaster resilience is built from the bottom-up. Without taking into account local social structures within a community, any top-down implementation of preparedness policy and procedures, such as introducing a community disaster committee, are likely to fail and could even harm the community and its networks it uses to protect, help and rebuild itself [51].

The significance of bringing together the case studies reviewed, and the consensus of their findings, is that this paper can offer tangible actions that can be used directly by DRR practitioners. The collective case study evidence reviewed suggests that social network mapping could be an invaluable tool for practitioners to understand how community resilience is built from the bottom-up. To date, social network mapping is not a common tool found within DRR practice, programming, and policy, remaining primarily in the hands of researchers who are only just making the connections between high-level development concepts, such as resilience, and community-level processes such as social support, response, and recovery. This is despite these types of bottom-up approaches being at the heart of the recent resilience-focused frameworks, such as the roadmap to resilience by the International Federation of the Red Cross (IFRC) [2]. The IFRC roadmap, for example, advocates that resilience-building processes must be people-centred and inclusive and that a key priority is to encourage communities to engage and connect with other stakeholders, such as nearby communities and government agencies [2]. The IFRC roadmap, in fact, recognises SNA as a tool within their roadmap, however it is not explicitly linked with the mapping of community networks to assess resilience nor are there suggestions of how to deploy SNA. However "the capacity of social network maps as a multi-purpose heuristic device is very useful—indeed necessary-if we want to explore ideas of community resilience and planning in the face of natural disasters" [57] (p. 0), suggesting that SNA and NBM are a critical tool for those working in the Global South to fully understand community disaster resilience.

\section{Innovation Within Social Network Mapping for Community Disaster Resilience}

Despite the initial positive start of connecting research to practice and even policy, many researchers, agencies, and disaster practitioners are yet to fully embrace social networks as a priority 
for preparedness. One potential reason for this lack of engagement is that much of the literature supporting these theories is nascent and relatively disparate and does not end up in the hands of those who need it most. Here, our review provides a first attempt to consolidate this emerging field of research and address it within the challenges of current community resilience and social capital research, with case studies drawn from the Global South. The studies we reviewed show that the creation of these social network maps is possible and these maps provide invaluable information that can be utilised by practitioners to make tangible improvements to a community. However, there are still limitations to using social network mapping for this type of DRR policy.

The major challenge of moving current SNA research forward is that social networks need to be viewed through what Rockenbauch and Sakdapolrak (2017) call a 'translocal' lens, one that not only assesses networks with regards to how they change over time but also over space as they become coupled with mobility [44]. Unlike the strands of research studied by Rockenbauch and Sakdapolrak (2017), DRR has the ability to explicitly account for the temporal dynamics of social networks by pinpointing a time when a disaster or event has occurred and comparing the changes in pre- and post-disaster networks. By having an event (real or hypothetical) to account for, it is proposed here that DRR research can lead the study of how social networks evolve and how this impacts a community's resilience [12,51-53]. The issue of spatiotemporality in the current literature [12] is pertinent when considering the importance in community disaster resilience of asking not only the question of resilience of whom, but also the resilience to what [59]. The mapping of social networks pre-, during and, post-disaster may provide insight about how a community's disaster resilience changes in response to a shock, underlining resilience not just as a property but also as a process. For example, Misra et al (2017) used the case study of a cyclone-affected community in coastal West Bengal (India) to identify how network structure and different key actors changed within the different phases of response, resulting in "a changing pattern of evolving networks during and after the disaster" [12] (p. 281). However, the scale of their study was limited; a sample size of 33 actors in a specific area, covering a timespan of thirteen months and one week post-event, was "not large enough for reaching a generalized inference in the area of disaster management" [12] (p. 295). Extending network analysis beyond the immediate community and over longer timespans is essential to capture the temporal and spatial change, not only of the community's networks but also their disaster resilience.

The ability to extend analyses across communities and timespans is currently a significant obstacle that SNA in community resilience measurement will need to overcome and, primarily, data collection is the cause of this obstacle facing most studies. Firstly, social network mapping is limited in geographical scope due to the traditional collection of the data using individual or household interviews and questionnaires. Whether it is the cost or logistics, extending SNA studies over greater geographical scales is likely to be difficult with traditional data collection, i.e., surveys and questionnaires. This method of data collection also limits the temporal analysis, where logistical and ethical reasons challenge the collection of data directly after a disaster hits (such as travelling to areas immediately after a disaster and potentially diverting resources away from the communities that need them more, e.g., shelter, food). Capturing the changes in the social networks during the different phases of the disaster management cycle, however, constitutes an important scope for future studies [12] and, as a result, innovation within social network measurement needs to occur to facilitate Rockenbauch and Sakdapolrak's (2017) translocal lens.

A potential answer to this problem is through the use of dynamic datasets, currently underutilised, within community resilience research. Here we propose that the growing intersection between big data and development, as promoted by the UN's data revolution [60], could be used within community resilience research. Dynamic network datasets, such as mobile phone metadata (known as call detail records) and social network datasets, could be used to map community connectivity through the reconstruction of community social networks. Already, research has shown that these datasets are able to reconstruct key human behaviours, including mobility, social contact, and expenditure, at fine spatial and temporal resolutions, at national spatial coverages, and over extensive time periods [61]. These 
outputs have been used to provide estimates on the total population of an area (useful for when a census is unavailable) [62], explore daily and seasonal travel patterns (national and internationally) $[63,64]$, and characterise these behaviours, along with different expenditure-top up routines, to predict socio-economic characteristics [65]. These insights have found multiple uses within sustainable development applications, including poverty estimation [66,67], epidemiology [68], and disaster response [69]. The need for investigating such an approach is timely considering the call within the Sendai Framework to promote and enhance the use of big data to support national measures for successful disaster risk communication [6]. Here we suggest that understanding the feasibility of using these types of data is a key step towards viewing community disaster resilience through the proposed 'translocal' lens and should be of significant interest and focus to those working to bring innovative insight into research within DRR and community resilience.

\section{Conclusions}

Social networks are seen as crucial to helping individuals and communities recover from and rebuild after a disaster. Whilst social networks have been traditionally evaluated in the wider concept of social capital, difficulties in the definition and operationalisation of social capital has led to the development of a subsection of literature specifically on mapping and measuring social networks for community resilience. Moving beyond social capital to focus on the structure, content, and geography of social networks is argued to hold great promise for the theorising and analysis of community resilience [58]. As a result, social networks, and their measurement, have become "one of the most promising developments for disaster risk reduction" [15] (p. 2713). This paper provides a review of recent case studies in the Global South to provide evidence to further substantiate this argument, showing that not only is a cohesive and robust methodology is developing around SNA and NBMs within community disaster resilience research, but that social network mapping is an imperative and essential step to truly understand how a community's resilience is built from the bottom-up. Without a thorough understanding of local structures and relationships, policies are likely to fail in the countries that need them most. Current studies are, however, limited by space (extending analysis beyond the community), time (showing dynamic changes in networks), and, when considered together, 'translocality' (understanding how changes occur over space). To move research forward, using Rockenbauch and Sakdalporak's (2017) translocal lens, we suggest here that dynamic datasets could provide proxies of people's social networks communities. Whilst these data have provided some new insights into social response during a disaster, their capacity has yet to be truly intersected with DRR policy and practice. Here it is proposed that mapping community social networks provides the ideal opportunity to explore the use of innovative data for community disaster resilience estimation. Overall, this paper advocates that the use of social network mapping and analysis should be utilised more widely, within resilience research and potential policy-influenced programming, to contribute towards fulfilling the current priorities outlined by international DRR frameworks.

Supplementary Materials: The following are available online at http:/ /www.mdpi.com/2071-1050/11/7/1943/s1.

Author Contributions: J.W., E.B. and A.J.T. contributed to the design and implementation of the review; J.W. wrote the manuscript with input and critical revisions from all authors.

Funding: This work was supported by the UK Economic and Social Research Council's Doctoral Training Programme which funds JW.

Conflicts of Interest: The authors declare no conflict of interest. The funders had no role in the design of the study; in the collection, analyses, or interpretation of data; in the writing of the manuscript, or in the decision to publish the results. 


\section{References}

1. Patel, S.S.; Rogers, M.B.; Amlôt, R.; Rubin, G.J. What Do We Mean by 'Community Resilience'? A Systematic Literature Review of How It Is Defined in the Literature. PLoS Curr. 2017, 9, 1-35. [CrossRef]

2. International Federation of Red Cross and Red Crescent Societies. Road Map to Community Resilience; International Federation of Red Cross and Red Crescent Societies: Geneva, Switzerland, 2016.

3. World Health Organization Regional Office for Europe. Strengthening Resilience: A Priority Shared by Health 2020 and the Sustainable Development Goals; World Health Organization Regional Office for Europe: Copenhagen, Denmark, 2017.

4. United Nations. A/RES/72/218: Disaster Risk Reduction (25 January 2019); United Nations: New York, NY, USA, 2018; pp. 1-8.

5. Aldrich, D.P.; Meyer, M.A. Social capital and community resilience. Am. Behav. Sci. 2015, 59, $254-269$. [CrossRef]

6. UNISDR. Sendai Framework for Disaster Risk Reduction; UNISDR: Geneva, Switzerland, 2015.

7. Claridge, T. Social Capital and Natural Resource Management: An Important Role for Social Capital? Master's Thesis, University of Queensland, Brisbane, Australia, 2004.

8. Bourdieu, P. The Forms of Capital. In Handbook of Theory and Research for the Sociology of Education; Ichardson, J.R., Ed.; Greenwood Publishing Group: New York, NY, USA, 1986; pp. 241-258.

9. Álvarez, E.C.; Romaní, J.R. La medición del capital social: Nuevas perspectivas. Gac. Sanit. 2017, 31, 57-61.

10. Asadzadeh, A.; Kötter, T.; Salehi, P.; Birkmann, J. Operationalizing a concept: The systematic review of composite indicator building for measuring community disaster resilience. Int. J. Disaster Risk Reduct. 2017, 25, 147-162. [CrossRef]

11. Woolcock, M.; Narayan, D. Social capital: Implications for development theory, research and policy. World Bank Res. Obs. 2000, 15, 225-249. [CrossRef]

12. Misra, S.; Goswami, R.; Mondal, T.; Jana, R. Social networks in the context of community response to disaster: Study of a cyclone-affected community in Coastal West Bengal, India. Int. J. Disaster Risk Reduct. 2017, 22, 281-296. [CrossRef]

13. Peters, K.; Langston, L.; Tanner, T.; Bahadur, A. Resilience across the Post-2015 Frameworks: How to Create Greater Coherence; Overseas Development Institute: London, UK, 2016.

14. Patel, R.B.; Gleason, K.M. The association between social cohesion and community resilience in two urban slums of Port au Prince, Haiti. Int. J. Disaster Risk Reduct. 2018, 27, 161-167. [CrossRef]

15. Alexander, D.E. Resilience and disaster risk reduction: An etymological journey. Nat. Hazards Earth Syst. Sci. 2013, 13, 2707-2716. [CrossRef]

16. Carpenter, S.; Walker, B.; Anderies, J.M.; Abel, N. From Metaphor to Measurement: Resilience of What to What? Ecosystems 2001, 4, 765-781. [CrossRef]

17. Folke, C. Resilience: The emergence of a perspective for social-ecological systems analyses. Glob. Environ. Chang. 2006, 16, 253-267. [CrossRef]

18. Weichselgartner, J.; Kelman, I. Geographies of resilience: Challenges and opportunities of a descriptive concept. Prog. Hum. Geogr. 2014, 39, 249-267. [CrossRef]

19. Manyena, S.B.; O'Brien, G.; O'Keefe, P.; Rose, J. Disaster resilience: A bounce back or bounce forward ability? Local Environ. 2011, 16, 417-424.

20. Pfefferbaum, B.; Horn, R.L.; Pfefferbaum, R.L. A conceptual framework to enhance community resilience using social capital. Clin. Soc. Work J. 2017, 45, 102-110. [CrossRef]

21. Paton, D.; Johnston, D. Disasters and communities: Vulnerability, resilience and preparedness. Disaster Prev. Manag. 2001, 10, 270-277. [CrossRef]

22. Maguire, B.; Hagan, P. Disasters and communities: Understanding social resilience. Aust. J. Emerg. Manag. 2007, 22, 16-20.

23. Cutter, S.; Barnes, L.; Berry, M.; Burton, C. A place-based model for understanding community resilience to natural disasters. Glob. Environ. Chang. 2008, 18, 598-606. [CrossRef]

24. Norris, F.H.; Stevens, S.P.; Pfefferbaum, B.; Wyche, K.F.; Pfefferbaum, R.L. Community resilience as a metaphor, theory, set of capacities, and strategy for disaster readiness. Am. J. Community Psychol. 2008, 41, 127-150. [CrossRef] [PubMed] 
25. Cutter, S.L.; Burton, C.G.; Emrich, C.T. Disaster Resilience Indicators for Benchmarking Baseline Conditions. J. Homel. Secur. Emerg. Manag. 2010, 7, 14. [CrossRef]

26. Sherrieb, K.; Norris, F.H.; Galea, S. Measuring Capacities for Community Resilience Resilience Measuring Capacities for Community. Soc. Indic. Res. 2010, 99, 227-247. [CrossRef]

27. Burton, C.G. A Validation of Metrics for Community Resilience to Natural Hazards and Disasters Using the Recovery from Hurricane Katrina as a Case Study. Ann. Assoc. Am. Geogr. 2015, 105, 67-86. [CrossRef]

28. Beccari, B. A comparative analysis of disaster risk, vulnerability and resilience composite indicators. PLoS Curr. 2016, 8. [CrossRef] [PubMed]

29. Sharifi, A. A critical review of selected tools for assessing community resilience. Ecol. Indic. 2016, 69, 629-647. [CrossRef]

30. Cai, H.; Lam, N.S.N.; Qiang, Y.; Zou, L.; Correll, R.M.; Mihunov, V. A synthesis of disaster resilience measurement methods and indices. Int. J. Disaster Risk Reduct. 2018, 31, 844-855. [CrossRef]

31. Lin, N. Building a Network Theory of Social Capital. Connections 1999, 22, 28-51.

32. Putnam, R.D. Social Capital: Measurement and Consequences. Isuma Can. J. Policy Res. 2001, 2, 41-51.

33. Adam, F.; Rončević, B. Social Capital: Recent Debates and Research Trends. Soc. Sci. Inf. 2003, 42, 155-183. [CrossRef]

34. Sabatini, F. Social capital as social networks: A new framework for measurement and an empirical analysis of its determinants and consequences. J. Socio-Econ. 2009, 38, 429-442. [CrossRef]

35. Krishna, A.; Shrader, E. Social Capital Assessment Tool. In Proceedings of the Conference on Social Capital and Poverty Reduction, Washington, DC, USA, 22-24 June 1999.

36. Van Deth, J.W. Measuring social capital: Orthodoxies and continuing controversies. Int. J. Soc. Res. Methodol. 2003, 6, 79-92. [CrossRef]

37. Wardrop, N.A.; Jochem, W.C.; Bird, T.J.; Chamberlain, H.R.; Clarke, D.; Kerr, D.; Bengtsson, L.; Juran, S.; Seaman, V.; Tatem, A.J. Spatially disaggregated population estimates in the absence of national population and housing census data. Proc. Natl. Acad. Sci. USA 2018, 115, 3529-3537. [CrossRef] [PubMed]

38. Borgatti, S.P.; Everett, M.G.; Johnson, J.C. Analyzing Social Networks; SAGE Publications: Thousand Oaks, CA, USA, 2013.

39. Scott, J. Social Network Analysis; SAGE: Thousand Oaks, CA, USA, 2012.

40. Granovetter, M.S. The Strength of Weak Ties. Am. J. Sociol. 1973, 78, 1360-1380. [CrossRef]

41. Lin, N.; Ensel, W.M.; Vaughn, J.C. Social Resources and Strength of Ties: Structural Factors in Occupational Status Attainment. Am. Sociol. Rev. 1981, 46, 393-405. [CrossRef]

42. Burt, R.S. The Contingent Value of Social Capital. Adm. Sci. Q. 1997, 42, 339-365. [CrossRef]

43. Borgatti, S.P.; Jones, C.; Everett, M.G. Network measures of social capital. Connections 1998, 21, 27-36.

44. Rockenbauch, T.; Sakdapolrak, P. Social networks and the resilience of rural communities in the Global South: A critical review and conceptual reflections. Ecol. Soc. 2017, 22, art10. [CrossRef]

45. Clarivate Analytics. Web of Science; Clarivate Analytics: Philadelphia, PA, USA, 2018.

46. World Bank. World Bank Country and Lending Groups. 2016. Available online: http://data.worldbank.org/ about/country-and-lending-groups (accessed on 27 March 2019).

47. Nakagawa, Y.; Shaw, R. Social Capital: A Missing Link to Disaster Recovery. Int. J. Mass Emerg. Disasters 2004, 22, 5-34.

48. Guarnacci, U. Joining the dots: Social networks and community resilience in post-conflict, post-disaster Indonesia. Int. J. Disaster Risk Reduct. 2016, 16, 180-191. [CrossRef]

49. Chaudhury, A.S.; Thornton, T.F.; Helfgott, A.; Ventresca, M.J.; Sova, C. Ties that bind: Local networks, communities and adaptive capacity in rural Ghana. J. Rural Stud. 2017, 53, 214-228. [CrossRef]

50. Yandong, Z. Social networks and reduction of risk in disasters: An example of Wenchuan earthquake. In Economic Stress, Human Capital, and Families in Asia; Springer: Dordrecht, The Netherlands, 2010; pp. 171-182.

51. Sanyal, S.; Routray, J.K. Social capital for disaster risk reduction and management with empirical evidences from Sundarbans of India. Int. J. Disaster Risk Reduct. 2016, 19, 101-111. [CrossRef]

52. Minamoto, Y. Social capital and livelihood recovery: Post-tsunami Sri Lanka as a case. Disaster Prev. Manag. Int. J. 2010, 19, 548-564. [CrossRef] 
53. Tobin, G.A.; Whiteford, L.M.; Murphy, A.D.; Jones, E.C.; McCarty, C. Modeling Social Networks and Community Resilience in Chronic Disasters: Case Studies from Volcanic Areas in Ecuador and Mexico. In Resilience and Sustainability in Relation to Natural Disasters: A Challenge for Future Cities; Springer: Berlin, Germany, 2014; pp. 13-24.

54. Hawkins, R.L.; Maurer, K. Bonding, Bridging and Linking: How Social Capital Operated in New Orleans following Hurricane Katrina. Br. J. Soc. Work 2010, 40, 1777-1793. [CrossRef]

55. Byg, A.; Herslund, L. Socio-economic changes, social capital and implications for climate change in a changing rural Nepal. GeoJournal 2016, 81, 169-184. [CrossRef]

56. Marin, A.; Gelcich, S.; Castilla, J.C.; Berkes, F. Exploring social capital in Chile's coastal benthic Comanagement system using a network approach. Ecol. Soc. 2012, 17, 13. [CrossRef]

57. Matin, N.; Taylor, R.; Forrester, J.; Pedoth, L.; Davis, B.; Deeming, H.; Fordham, M. Mapping of Social Networks as Measures of Social Resilience of Agents. Deliverable 4.2. emBRACE project. 2015. Available online: www.embrace-eu.org/outputs (accessed on 27 February 2019).

58. MacGillivray, B.H. Beyond social capital: The norms, belief systems, and agency embedded in social networks shape resilience to climatic and geophysical hazards. Environ. Sci. Policy 2018, 89, 116-125. [CrossRef]

59. Cutter, S.L. Resilience to What? Resilience for Whom? Geogr. J. 2016, 182, 110-113. [CrossRef]

60. UN Data Revolution Group. A World That Counts: Mobilising the Data Revolution for Sustainable Development; UN Data Revolution Group: New York, NY, USA, 2014.

61. Blondel, V.D.; Decuyper, A.; Krings, G. A survey of results on mobile phone datasets analysis. EPJ Data Sci. 2015, 4, 10. [CrossRef]

62. Douglass, R.W.; Meyer, D.A.; Ram, M.; Rideout, D.; Song, D. High resolution population estimates from telecommunications data. EPJ Data Sci. 2015, 4, 4. [CrossRef]

63. Deville, P.; Linard, C.; Martin, S.; Gilbert, M.; Stevens, F.R.; Gaughan, A.E.; Blondel, V.D.; Tatem, A.J. Dynamic population mapping using mobile phone data. Proc. Natl. Acad. Sci. USA 2014, 111, 15888-15893. [CrossRef] [PubMed]

64. Erbach-Schoenberg, E.Z.; Alegana, V.A.; Sorichetta, A.; Linard, C.; Lourenço, C.; Ruktanonchai, N.W.; Graupe, B.; Bird, T.J.; Pezzulo, C.; Wesolowski, A.; et al. Dynamic denominators: The impact of seasonally varying population numbers on disease incidence estimates. Popul. Health Metr. 2016, 14, 35. [CrossRef]

65. Fernando, L.; Surendra, A.; Lokanathan, S.; Gomez, T. Predicting Population-level Socio-economic Characteristics Using Call Detail Records (CDRs) in Sri Lanka. In Proceedings of the Fourth International Workshop on Data Science for Macro-Modeling with Financial and Economic Datasets, Houston, TX, USA, 15 June 2018.

66. Blumenstock, J.; Cadamuro, G.; On, R. Predicting poverty and wealth from mobile phone metadata. Science 2015, 350, 1073-1076. [CrossRef]

67. Steele, J.E.; Sundsøy, P.R.; Pezzulo, C.; Alegana, V.A.; Bird, T.J.; Blumenstock, J.; Bjelland, J.; Engø-Monsen, K.; de Montjoye, Y.-A.; Iqbal, A.M. Mapping poverty using mobile phone and satellite data. J. R. Soc. Interface 2017, 14, 20160690. [CrossRef]

68. Bengtsson, L.; Gaudart, J.; Lu, X.; Moore, S.; Wetter, E.; Sallah, K.; Rebaudet, S.; Piarroux, R. Using Mobile Phone Data to Predict the Spatial Spread of Cholera. Sci. Rep. 2015, 5, 8923. [CrossRef] [PubMed]

69. Bengtsson, L.; Lu, X.; Thorson, A.; Garfield, R.; von Schreeb, J. Improved response to disasters and outbreaks by tracking population movements with mobile phone network data: A post-earthquake geospatial study in haiti. PLoS Med. 2011, 8, e1001083. [CrossRef] [PubMed]

(C) 2019 by the authors. Licensee MDPI, Basel, Switzerland. This article is an open access article distributed under the terms and conditions of the Creative Commons Attribution (CC BY) license (http:// creativecommons.org/licenses/by/4.0/). 